\title{
Robotic assisted Heller myotomy: indications, techniques and outcomes
}

\author{
Ernest G. Chan, Inderpal S. Sarkaria
}

Division of Thoracic Surgery, Department of Cardiothoracic Surgery, the University of Pittsburgh Medical Center and the University of Pittsburgh School of Medicine, Pittsburgh, PA, USA

Contributions: (I) Conception and design: All authors; (II) Administrative support: All authors; (III) Provision of study materials or patients: All authors; (IV) Collection and assembly of data: All authors; (V) Data analysis and interpretation: All authors; (VI) Manuscript writing: All authors; (VII) Final approval of manuscript: All authors.

Correspondence to: Inderpal Sarkaria, MD. Vice Chairman, Clinical Affairs, Director, Robotic Thoracic Surgery, Shadyside Medical Building, 5200 Centre Ave, Suite 715, Pittsburgh, PA 15232, USA. Email: sarkariais@upmc.edu.

\begin{abstract}
Achalasia is defined as an esophageal motility disorder that is characterized by two components: impaired peristalsis and the inability of the lower esophageal sphincter to relax. While the etiology is unknown, many studies suggest that the pathophysiology lies in the destruction of the ganglion cells of the mesenteric plexus located in the muscularis propria layer of the esophagus. Treatment of achalasia begins with various endoscopic interventions. However, these endoscopic interventions can require multiple interventions and are not free of morbidity and mortality. The definitive treatment for achalasia associated with superior long-term symptom relief is a Heller myotomy. The Heller myotomy was first performed by Dr. Ernest Heller on April 14, 1,913 where he used an anterior and posterior incision to obliterate the dysfunctional LES in a patient with achalasia. Inevitably, the Heller myotomy procedure has evolved most notably in the 90s where the first minimally invasive esophagomyotomies were reported both with thoracoscopic and laparoscopic approaches. The first cases of robotic assisted Heller myotomy (RAHM) were reported in 2001. Since then, a number of studies have reported its equivalence in outcomes to the laparoscopic, endoscopic, and open approaches as well as areas in which the robot may prove to be superior.
\end{abstract}

Keywords: Achalasia; heller myotomy; robotic assisted heller myotomy (RAHM); minimally invasive esophageal surgery

Received: 03 January 2020. Accepted: 19 March 2020; Published: 10 January 2021.

doi: 10.21037/shc-2019-mies-09

View this article at: http://dx.doi.org/10.21037/shc-2019-mies-09

\section{Introduction}

Achalasia is defined as an esophageal motility disorder that is characterized by two components: impaired peristalsis and the inability of the lower esophageal sphincter to relax (1). Although it is a rare disorder, it is the most common primary motility disorder of the esophagus and affects 0.4 1.1 per 100,000 persons annually $(1,2)$. While the etiology is unknown, many studies suggest that the pathophysiology lies in the destruction of the ganglion cells of the mesenteric plexus located in the muscularis propria layer of the esophagus $(1,3)$. Pathologic findings include diminished myenteric ganglia, collagen deposition, and lymphocytic infiltration. Some postulate that a viral infection is the cause of this disease (4). Others attribute its etiology to an autoimmune disorder that targets nitric oxide synthase (5). Nevertheless, the consequence is an unopposed sympathetic response and increased pressure at the level of the LES. This will result in a functional obstruction of the esophagus.

Achalasia is a slowly progressive disease with a peak incidence between 20-40 with no predilection for either gender (2). The time of from onset of symptoms to presentation is approximately 6 years (6). The most common symptom is dysphagia. This usually starts with 
issues passing solid foods which will ultimately progress to liquids. Because there is difficulty in the progression of foods down the esophagus, $60-90 \%$ of patients will complain of regurgitation of food, leading to aspiration and chronic pulmonary symptoms (4). Additional symptoms include weight loss, aspiration, recurrent pneumonia, chronic cough, and heartburn from the stasis of food and acid. Because heartburn may complication the work-up of these patients, diagnosis may be delayed as a trial of PPIs are usually unsuccessful (5). If left untreated, this persistent obstruction will lead to food stasis, and ultimately esophageal dilation which will eventually assume a sigmoid appearance on barium radiograph (4). Acid fermentation products of retained food may occur at this end-stage of the disease, resulting in burning retrosternal discomfort.

Treatment of achalasia begins with various endoscopic interventions. Dilation of the lower esophageal sphincter with either pneumatic balloons or savory dilators allows for disruption of muscular fibers of the LES while preserving the esophageal mucosa. While associated with an esophageal perforation of up to $4 \%$ in some series. Longterm symptomatic relief of dysphagia and regurgitation is obtainable in $60-75 \%$ of patients on the first dilation. Additional endoscopic interventions include botulinum toxin injections to relax the pathologic LES, but these results last less than 6 months in most patients and multiple injections are necessary for consistent long-term relief $(7,8)$.

Therefore, the definitive treatment for achalasia associated with superior long-term symptom relief is a Heller myotomy. The Heller myotomy was first performed by Dr. Ernst Heller on April 14, 1913 where he used an anterior and posterior incision to obliterate the dysfunctional LES in a patient with achalasia (9). Since the first reported case, the Heller myotomy procedure has evolved most notably in the 90s where the first minimally invasive esophagomyotomies were reported both with a thoracoscopic and laparoscopic approaches $(10,11)$. Moreover, several randomized controlled trials have shown its superiority to that of endoscopic dilation and botulinum toxin injections $(12,13)$. Lastly, since the LES is being disrupted by this procedure, an additional step of a partial fundoplication has since been added by most surgeons to reduce the risk of gastroesophageal reflux postoperatively (14). The study was conducted in accordance with the Declaration of Helsinki (as revised in 2013). This was a review of published studies. Informed consent was obtained from the patients for procedures at our center.

\section{Diagnosis and work-up}

The diagnosis of achalasia first begins with a history and physical exam. Patients will report complaints of progressive dysphagia starting with solid foods. This will inevitably progress to liquids. In the final stages of achalasia, patients may also have complaints of heartburn which is likely secondary to acidic fermentation of retained food in the esophagus. In the early stages of the disease, chest radiography may appear normal. However, as it progresses, it is possible to see a widened mediastinum, and air fluid level, absence of gastric air bubble, and even aspiration pneumonitis on radiography. A barium swallow will typically show absence of peristalsis in the body of the esophagus with a distal narrowing of the LES culminating in a "bird's beak" configuration. A sigmoid appearing esophagus may be a sign of long-standing achalasia as well.

Currently, high resolution manometry (HRM) is the gold standard diagnostic test for achalasia. Classic conventional manometric findings include a failure of relaxation of the LES with swallowing along with esophageal aperistalsis. Additional results show an elevated lower esophageal baseline pressure with an elevated resting LES pressure. With HRM, data obtained can be converted into a topographical plot using interpolation called Clouse Plots. These plots offer a dynamic assessment of the LES function at the start of a swallowing cycle as well as assess esophageal motor function concurrently. This has allowed clinicians with further characterizing achalasia into three types: type 1 with minimal contractility of the esophageal body, type II with intermittent periods of panesophageal pressurization, and type III with premature or spastic distal esophageal contractions. These types of achalasia will prove important as each has a distinct response to various treatment modalities (15).

Endoscopic evaluation is important for complete work-up of a patient with achalasia. On endoscopy, a narrowed LES is typically encountered with failure to expand until enough pressure and insufflation is used, resulting in a classic "pop" once it is traversed. A dilated tortuous esophagus filled with undigested food may be present in patients with longstanding untreated achalasia. It is important to look for additional pathology such as ulcers, esophagitis, candidiasis, as well as malignancy as this can occur in $2-4 \%$ of 
patients $(16,17)$.

\section{Indications for surgical treatment}

Because there is currently no cure for achalasia, the main goals of treatment of achalasia are to slow the progression of disease as well as provide symptomatic relief. Once patients are properly diagnosed and an adequate evaluation of the esophagus is obtained, patients have several treatment options. Medically, patients can be offered oral nitrates and calcium channel blockers in an attempt to facilitate LES relaxation. Endoscopic botulinum toxin and pneumatic dilation are alternate options. Botulinum toxin will block the release of acetylcholine in the LES whereas endoscopic dilation will cause fracturing of the muscularis propria in the LES. Both result in relieving LES pressure but come with unique risks. Botulinum toxin injection has been shown to fail at roughly 6 months for many patients, necessitating multiple injections $(6,18-20)$. Moreover, while pneumatic dilation may have longer lasting effects, it is associated with a $2-7 \%$ risk of esophageal perforation (20). Both interventions may cause significant fibrosis and scarring within the esophageal muscle as well.

In patients who are unfit for surgery or have very early onset disease, endoscopic procedures may be recommended as primary treatment with the anticipation that future interventions will be needed. In patients with progressive disease and failed multiple previous endoscopic attempts, surgical myotomy is the definitive treatment of choice for those who are fit for surgery. While the original operation performed by Heller included an open approach with an anterior and posterior longitudinal myotomy, the procedure has evolved substantially to include endoscopic, laparoscopic, and now robotic assisted approaches.

Unfortunately, not all patients present with early stage achalasia. In patients with signs of end-stage achalasia, along with the hypertensive LES, the dilated nature and tortuosity of the diseased esophagus can be anticipated to result in persistent symptoms of dysphagia, aspiration, and regurgitation despite myotomizing the hypertensive LES. Therefore, in patients with end-stage achalasia of the esophagus, near complete removal of the disease organ by esophagectomy may ultimately be required.

\section{Surgical technique}

Once patients are scheduled for surgery, they are educated to start a clear liquid diet several days prior to surgery in attempt to minimize the food debris intraoperatively. Depending on the severity of the disease, some patients may require admission immediately prior to the day of surgery to undergo endoscopic dis-impaction of the diseased esophagus. In severe cases, this may take several hours and will minimize the chances of aspiration at the time of surgery, and also minimize excessive insufflation of the bowel at the time of the operation.

On the day of surgery, the patient is brought into the operating room, positioned supine with their head elevated, placed under general anesthesia and subsequently intubated. The conduct of anesthesia is vital to prevent aspiration, which can be a significant source of morbidity in these patients, and prevent proceeding with operation in severe cases. Rapid sequence induction with cricoid pressure is often advised. Keeping the patient in a semi-recumbent position prior to induction may also be advisable. An arterial line may be placed for hemodynamic monitoring if indicated. Careful endoscopic evaluation is performed with minimal insufflation by the surgeon to avoid overdistention of the bowel and loss of domain and visualization within the abdomen. Once occult malignancy is ruled out and the esophagus is thoroughly emptied, the stomach is decompressed and the patient is properly positioned. A footboard is placed to support sufficient reverse Trendelenburg position for hiatal exposure. We prefer to keep the arms out at 45 degrees but the left arm can be tucked at the surgeon's discretion (Figure 1).

We are currently utilizing a six-port configuration (Figure 2). As in our laparoscopic approach to Heller myotomy, appropriate port placement is pivotal to a successful operation due to the mediastinal dissection necessary for an adequate myotomy. The midline from the xiphoid to the level of the umbilicus is marked and divided into thirds. A camera incision is placed just left of the midline approximately half the distance from the xiphoid to the umbilicus. A left lateral subcostal 5-mm or 8 -mm incision (dependent upon the robotic platform used) is marked for utilizing the robotic atraumatic grasper for assistance. Left and right midclavicular $8-\mathrm{mm}$ ports are placed in the epigastrium. The robotic ultrasonic shears are placed in the "right hand" robotic ultrasonic shears, and bipolar forceps in the robotic "left hand". The "left hand" port is placed closer to the midline to minimize instrument angulation between the shaft of the instrument and the right crural pilar during trans-hiatal intra-thoracic dissection. An additional 11-mm laparoscopic port is positioned in the right para-umbilical region as the beside 


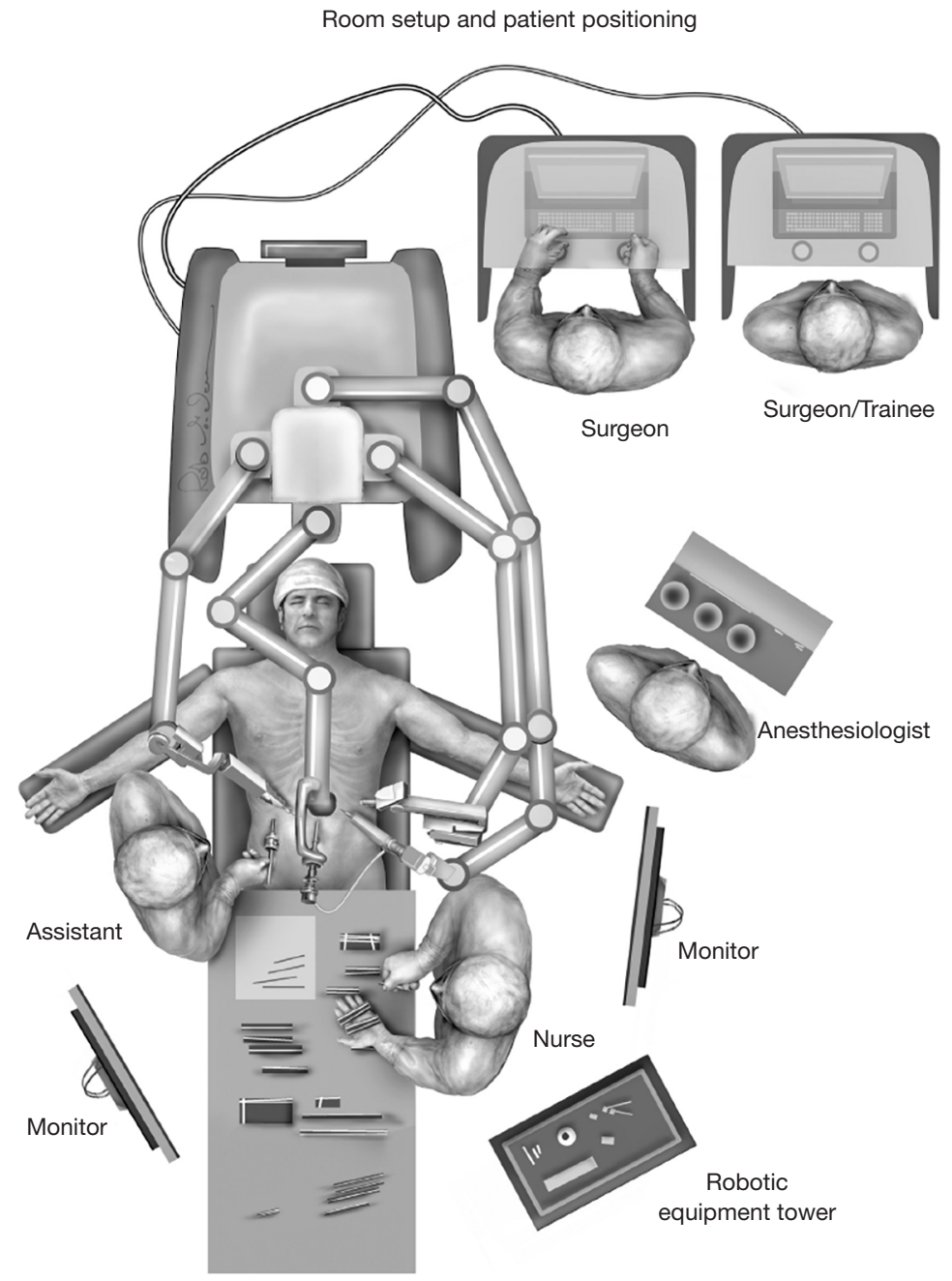

Figure 1 Operative room set up for robotically assisted Heller myotomy.

assistant port for suction, retraction, and introduction of sutures. Lastly, the liver retractor is inserted through a right lateral 5-mm subcostal port for elevation of the left lobe of the liver to expose the hiatus. It is optimal to maintain at least $8-10 \mathrm{~cm}$ distance between robotic ports to minimize collisions, although more recent platforms allow for closer spacing of the ports with fewer collisions. $15 \mathrm{mmHg}$ of $\mathrm{CO}_{2}$ insufflation is provided for optimal peritoneal distension and visualization. Port placement is summarized in Figure 2.

After reverse Trendelenburg is achieved, we proceed to dissect around the hiatus first by transecting the gastrohepatic ligament to fully visualize the right crus. Circumferential dissection of the esophagus is only necessary in the presence of a hiatal hernia or a tortuous esophagus. If there is no evidence of any hiatal hernia or a tortuous esophagus, extensive circumferential dissection of the esophagus is not advised. While dissecting the esophagus from its surrounding structures, care must be taken to avoid damaging the peritoneal lining overlying the crural pillars and exposing the muscle. If the peritoneal lining is stripped from the underlying muscle, suture integrity, approximation of the crural pillars and closure may be at higher risk for dehiscence. We believe adequate mediastinal mobilization and exposure of enough esophageal length is necessary to perform an adequate myotomy. Visualizing the arealor attachments is critical during this portion of the case as it assures that the surgeon is safely visualizing the mediastinal boundaries and its 


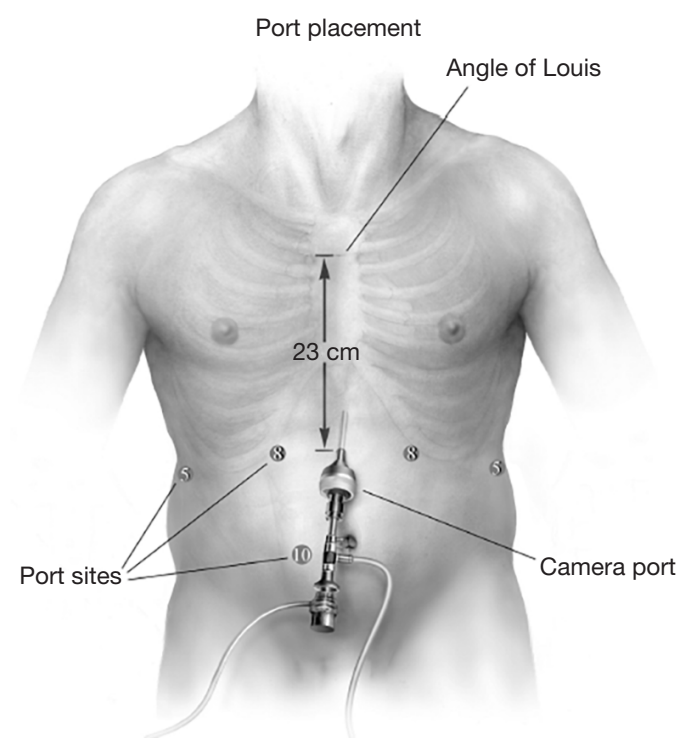

Figure 2 Six port configuration for a robotically assisted Heller myotomy. First, a camera incision is placed just left of the midline approximately half the distance from the xiphoid to the umbilicus. Second, a left lateral subcostal $5-\mathrm{mm}$ incision is marked for utilizing the robotic atraumatic grasper for assistance. Third, left midclavicular 8 -mm port is marked at the left epigastrium 1 fingerbreath below the ribs for the "robotic right hand" and for the robotic ultrasonic shears. Fourth, an additional 8th right midclavicular port is placed for the bipolar forceps which will be the "robotic left hand". Fifth, a 5-mm laparoscopic port is positioned right to the midline and at least 1 handbreath below the 10-12-mm port previously placed to allow for bedside assistance. The 6th port is a right lateral $5-\mathrm{mm}$ subcostal port for elevation of the left lobe of the liver by a liver retractor to clearly expose the hiatus.

contents (pleurae, pericardium, esophagus, vagal nerves). The surgeon must visualize the pleural reflection to avoid causing an iatrogenic pneumothorax. If the pleural reflection is violated, adequate communication between the surgical and anesthesia teams are necessary to identify and treat the pneumothorax in a timely fashion if there is evidence of hemodynamic or respiratory compromise. Simply evacuating the pneumothorax through the pleural defect with a laparoscopic suction device would be the most effective maneuver. The defect may also be closed with clips. If these maneuvers fail, insertion of a small-bore pigtail catheter under direct visualization be performed for definitive treatment. It is paramount to visualize the anterior vagal nerve in order to preserve it during the

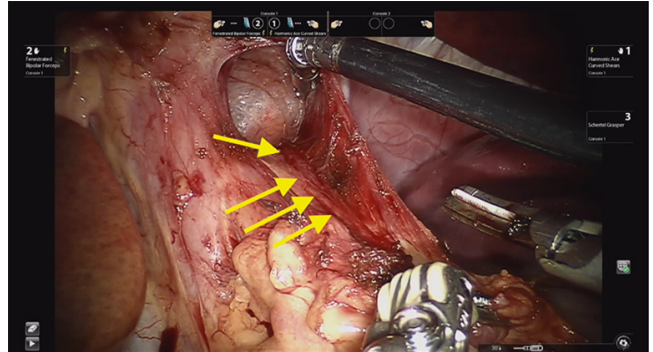

Figure 3 Visualizing the arealor attachments is critical during this portion of the case as it assures that the surgeon is safely visualizing the mediastinal boundaries and its contents (pleurae, pericardium, esophagus, vagal nerves). In addition, it is paramount to visualize the anterior vagal nerve in order to preserve it during the mediastinal dissection and fat pad dissection (yellow arrows).

mediastinal dissection (Figure 3).

\section{Myotomy}

Following fundus mobilization, the gastric fat pad is mobilized medially off the stomach and distal esophagus to adequately and accurately visualize the gastroesophageal junction. Care must be taken to mobilized the anterior/ left vagus nerve with the fat pad. The robotic platform provides excellent visualization of the muscle fibers of the esophagus. The myotomy is then carefully performed utilizing a combination of energy and blunt dissection. The myotomy is extended approximately $6-8 \mathrm{~cm}$ proximal to the GE junction onto the esophagus, or further if needed until relatively normal thickness muscle is encountered. The myotomy is then continued caudally 2 to $3 \mathrm{~cm}$ onto the stomach (Figure 4). It is important to continue the myotomy down through the sling fibers. Careful attention is noted to the esophageal mucosa to ensure its integrity is kept. If energy is used to perform the myotomy, it is important to avoid heat burns on the esophageal mucosa. We prefer the use of the Harmonic Scalpel. To avoid thermal injury to the mucosa, the insulated blade is placed adjacent to the mucosa with the heated metal blade facing away. The metal blade can also be cooled on more durable structures such as the liver or the diaphragm. After an adequate myotomy is completed, an endoscope is carefully advanced into the esophagus towards the GE junction with air insufflation to perform a leak test with the myotomy under saline irrigation. If a perforation is observed, it should be repaired at this time. 


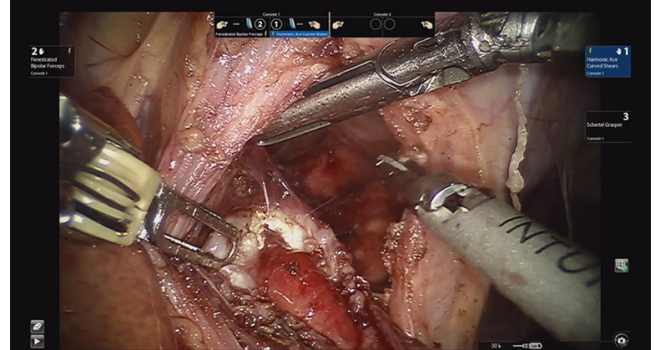

Figure 4 The myotomy is carefully performed utilizing a combination of energy and blunt dissection the myotomy is extended 8 to $10 \mathrm{~cm}$ proximal to the GE junction onto the esophagus and 2-3 caudally onto the stomach. It is important to continue the myotomy down to the sling fibers. If energy is used, it is important to avoid heat burns onto the esophageal mucosa. With the Harmonic Scalpel, the insulated blade is typically placed on the mucosa with the heated metal blade facing away. The metal blade can further be cooled down on more durable surround structures such as the liver or diaphragm.

\section{Establishing anti-reflux barrier}

Due to the disruption of the LES, we generally perform an anti-reflux fundoplication to minimize the risk of significant gastroesophageal reflux. Surgeon preference, patient symptoms and preoperative physiologic testing and radiographic studies assessing esophageal motility dictate this step of the procedure. It is our preference to perform a partial 180-degree anterior Dor fundoplication. Once the myotomy is complete, the fundus of the stomach is carefully inspected to ensure enough short gastric arteries are taken to perform a tension free anterior fundoplication. The stomach is folded anteriorly to approximate the line of the short gastric arteries to the right and left crus (Figure 5). Our general approach utilizes a single suture line, although a double suture line may be used as well.

\section{Post-operative management}

The patient is typically extubated and transferred to the post-operative care unit or intensive care unit depending on the patient's comorbidities. Patients ambulate and undergo a swallow esophagram on post-operative day one. If the study is negative for a leak and post-operative anatomy is unremarkable, the nasogastric tube is removed and the patient's diet is advanced to a clear liquid diet and subsequent full diet. If dysphagia is significantly improved, a soft diet may be started in relatively short order. Patients

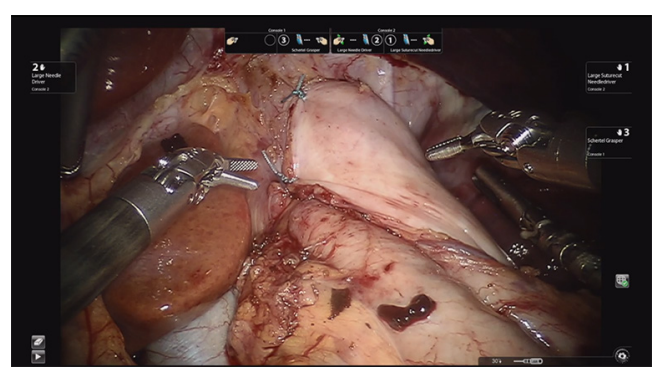

Figure 5 Once the fundus of the stomach is freed from its surrounding structures, it is folded anteriorly approximating the line of the short gastric arteries to the right and left crus to perform an anterior Dor fundoplication.

are typically discharged on postoperative day $1-2$. Pain is commonly managed with acetaminophen, ibuprofen, and augmented with low dose oral liquid narcotic only if needed. Once patients are discharged, they are given simethicone to manage bloating, acetaminophen for pain, and may remain on a proton pump inhibitor or H2-blocker therapy for reflux in the early postoperative period. All patients are re-evaluated 2 weeks after surgery, and then yearly with an esophagram.

\section{Outcomes following robotic assisted Heller myotomy (RAHM)}

Table 1 includes all studies comparing primary RAHM with other surgical techniques. Currently, there are four retrospective studies comparing outcomes in adult patients undergoing primary RAHM to its laparoscopic (LHM) counterpart, one study comparing it to the per oral endoscopic myotomy (POEM) procedure, one study comparing RAHM with both POEM and LHM, and one study comparing RAHM with LHM and the open approach. Operative times were longer in most RAHM groups compared to LHM and POEM. This was found to be statistically significant in both studies including the POEM procedure and 2 out of 5 studies including a laparoscopic group. This is consistent with the operation with regards to the POEM group as all of these studies performed a fundoplication in the overwhelming majority of their cases both in their RAHM and LHM groups. In addition, each of these studies note that operative times were improving in the more recent cases reported in their studies. While conversion rates and mortality were virtually identical in the studies that report these findings, the intraoperative 
Table 1 Literature review of robotic assisted heller myotomy (RAHM) in comparison with other surgical techniques

\begin{tabular}{|c|c|c|c|c|c|c|c|c|c|c|}
\hline Study & Year & $\begin{array}{l}\text { Study groups } \\
{[\mathrm{n}]}\end{array}$ & $\begin{array}{c}\text { Operative } \\
\text { time (minutes) }\end{array}$ & $\begin{array}{l}\text { Perforation } \\
\text { rate }(\%)\end{array}$ & $\begin{array}{c}\text { Conversion } \\
\text { rate }(\%)\end{array}$ & $\begin{array}{c}\text { Mortality } \\
(\%)\end{array}$ & $\begin{array}{c}\text { Morbidity } \\
(\%)\end{array}$ & $\begin{array}{l}\text { Length of } \\
\text { stay (days) }\end{array}$ & $\begin{array}{l}\text { Follow-up } \\
\text { (months) }\end{array}$ & $\begin{array}{c}\text { Satisfaction } \\
\text { rate }(\%)\end{array}$ \\
\hline $\begin{array}{l}\text { Shaligram } \\
\text { et al. (21) }\end{array}$ & 2012 & $\begin{array}{l}\text { RAHM [149] vs. } \\
\text { LHM [2116] vs. } \\
\text { Open [418] }\end{array}$ & $\mathrm{nr}$ & $\mathrm{nr}$ & $\mathrm{nr}$ & $\begin{array}{c}0 \text { vs. } 0.14 \\
\text { vs. } 0.24 ; \\
\quad(P=1)\end{array}$ & $\begin{array}{c}4.02 \text { vs. } \\
\text { 5.19 vs. 9.08; } \\
\quad(P=0.02)\end{array}$ & $\begin{array}{c}2.42 \text { vs. } 2.7 \\
\text { vs. } 4.42 \\
(\mathrm{P}=0.0001)\end{array}$ & $\mathrm{nr}$ & $\mathrm{nr}$ \\
\hline $\begin{array}{l}\text { Ali et al. } \\
\text { (22) }\end{array}$ & 2020 & $\begin{array}{l}\text { RAHM [44] vs. } \\
\text { LHM [40] vs. } \\
\text { POEM [87] }\end{array}$ & $\begin{array}{c}183.5 \text { vs. } \\
157 \text { vs. } 169 \\
(P=0.01)\end{array}$ & $\begin{array}{c}0 \text { vs. } 17.5 \\
\text { vs. } 1.1 ; \\
(\mathrm{P}=0.001)\end{array}$ & $\begin{array}{c}0 \text { vs. } 5 \\
\text { vs. } 0 \\
(\mathrm{P}=0.054)\end{array}$ & $\begin{array}{c}0 \text { vs. } 0 \text { vs. } \\
0 ;(-)\end{array}$ & $\begin{array}{c}2.3 \text { vs. } 0 \\
\text { vs. } 0 ; \\
(\mathrm{P}=0.49)\end{array}$ & $\begin{array}{c}1 \text { vs. } 1 \\
\text { vs. } 1 \\
(\mathrm{P}=0.29)\end{array}$ & $\mathrm{nr}$ & $\mathrm{nr}$ \\
\hline $\begin{array}{l}\text { Khashab } \\
\text { et al. (23) }\end{array}$ & 2017 & $\begin{array}{l}\text { RAHM [52] vs. } \\
\text { POEM [52] }\end{array}$ & $\begin{array}{c}263 \text { vs. } 106 \\
(p<0.001)\end{array}$ & $\begin{array}{c}0 \text { vs. } 7.7 \\
\quad(P=n r)\end{array}$ & $\mathrm{nr}$ & 0 vs. $0 ;(-)$ & $\begin{array}{l}9.6 \text { vs. } 19.2 \\
\quad(P=0.26)\end{array}$ & $\begin{array}{l}2.3 \text { vs. 1.9; } \\
(P=0.18)\end{array}$ & $\begin{array}{l}8.9 \text { vs. } 15.6 \\
\quad(P=0.04)\end{array}$ & $\begin{array}{c}88.50 \text { vs. } \\
94.3 ;(P=0.48)\end{array}$ \\
\hline $\begin{array}{l}\text { Horgan } \\
\text { et al. (24) }\end{array}$ & 2005 & $\begin{array}{l}\text { RAHM [59] vs. } \\
\text { LHM [61] }\end{array}$ & $\begin{array}{c}141 \text { vs. } 122 ; \\
\quad(P=0.03)\end{array}$ & $\begin{array}{l}0 \text { vs. 16; } \\
(p<0.01)\end{array}$ & 0 vs. $0 ;(-)$ & 0 vs. $0 ;(-)$ & $\begin{array}{c}3.4 \text { vs. } 1.6 \\
\quad(P=n r)\end{array}$ & $\begin{array}{c}1.5 \text { vs. 2.2; } \\
\quad(P=n r)\end{array}$ & $\begin{array}{c}18 \text { vs. 22; } \\
(\mathrm{P}=\mathrm{nr})\end{array}$ & $\begin{array}{c}92 \text { vs. 90; } \\
\quad(\mathrm{P}=\mathrm{nr})\end{array}$ \\
\hline $\begin{array}{l}\text { Huffmanm } \\
\text { et al. (25) }\end{array}$ & 2007 & $\begin{array}{l}\text { RAHM [24] vs. } \\
\text { LHM [37] }\end{array}$ & $\begin{array}{c}355 \text { vs. } 287 \\
\quad(P=n r)\end{array}$ & $\begin{array}{c}0 \text { vs. 8.1; } \\
\quad(P=n r)\end{array}$ & $\mathrm{nr}$ & $\mathrm{nr}$ & $\mathrm{nr}$ & $\begin{array}{l}2.8 \text { vs. 2.6; } \\
\quad(P=n r)\end{array}$ & $\begin{array}{c}15 \text { vs. 43; } \\
\quad(P=n r)\end{array}$ & $\mathrm{nr}$ \\
\hline $\begin{array}{l}\text { Perry } \\
\text { et al. (26) }\end{array}$ & 2014 & $\begin{array}{l}\text { RAHM [56] vs. } \\
\text { LHM [75] }\end{array}$ & $\begin{array}{c}133 \text { vs. } 121 \\
(P=0.14)\end{array}$ & $\begin{array}{c}0 \text { vs. 15.8; } \\
(P=0.01)\end{array}$ & 0 vs. $0 ;(-)$ & 0 vs. $0 ;(-)$ & $\mathrm{nr}$ & $\begin{array}{l}1 \text { vs. } 2 \\
(p<0.01)\end{array}$ & $\begin{array}{l}109 \text { vs. } \\
\text { 109; (-) }\end{array}$ & $\begin{array}{c}97 \text { vs. } 91 \\
(P=0.44)\end{array}$ \\
\hline $\begin{array}{l}\text { Sánchez } \\
\text { et al. (27) }\end{array}$ & 2012 & $\begin{array}{c}\text { RAHM [13] vs. } \\
\text { LHM [18] }\end{array}$ & $\begin{array}{c}79 \text { vs. } 76 ; \\
(P=n s)\end{array}$ & $\begin{array}{c}0 \text { vs. 5.5; } \\
(\mathrm{P}=\mathrm{ns})\end{array}$ & 0 vs. $0 ;(-)$ & 0 vs. $0 ;(-)$ & 0 vs. $0 ;(-)$ & $\begin{array}{c}2 \text { vs. 2.2; } \\
(\mathrm{P}=\mathrm{nr})\end{array}$ & $\begin{array}{c}18 \text { vs. } 18 \\
(P=n r)\end{array}$ & $\begin{array}{c}100 \text { vs. 94.5; } \\
\quad(P=n s)\end{array}$ \\
\hline
\end{tabular}

perforation rate was significantly lower in all robotic groups. Across 5 studies that report perforation rates, there were a total of zero intraoperative perforations reported compared to rates between $1.1 \%$ to $7.7 \%$ in the POEM cohorts and $5.5-17 \%$ in the LHM groups. Postoperative morbidity was similar between all cohorts. Length of stay was also similar in all groups across all 7 studies. Lastly, while there was a slightly higher reported rate of patient satisfaction with RAHM, this difference was not found to be statistically difference in the 4 studies that reported patient satisfaction.

\section{Conclusions}

In conclusion, RAHM is a safe and feasible operation for patients with a diagnosis of achalasia. When compared to its laparoscopic and endoscopic counterparts, current studies identify longer operative times although the effect of the early learning curve is thought to play a significant role. Additional studies will be needed to assess the learning curve to truly report an accurate comparison. Overall, implementation of the robotic platform to the Heller myotomy procedure is associated with excellent overall outcomes similar to other approaches, with equivalent patient satisfaction rates. Interestingly, perhaps due to the increased control over the conduct of the operation afforded the surgeon by the improved visualization and instrumentation, significantly lower rates of intraoperative perforations have been identified compared to alternative methods. Given the current state of evidence, RAHM may be considered an acceptable and safe alternative to esophageal myotomy for achalasia.

\section{Acknowledgments}

Funding: None.

\section{Footnote}

Provenance and Peer Review: This article was commissioned by the Guest Editor (Ghulam Abbas) for the series "Minimally Invasive Esophageal Surgery" published in Shanghai Chest. The article was sent for external peer review organized by the Guest Editor and the editorial office.

Conflicts of Interest: Both authors have completed the ICMJE uniform disclosure form (available at http://dx.doi. org/10.21037/shc-2019-mies-09). The series "Minimally Invasive Esophageal Surgery" was commissioned by the editorial office without any funding or sponsorship. ISS reports fees for consulting and education for Intuitive Surgical, Inc. EGC has no other conflicts of interest to declare. 
Ethical statement: the authors are accountable for all aspects of the work in ensuring that questions related to the accuracy or integrity of any part of the work are appropriately investigated and resolved. The study was conducted in accordance with the Declaration of Helsinki (as revised in 2013). This was a review of published studies. Informed consent was obtained from the patients for procedures at our center.

Open Access Statement: This is an Open Access article distributed in accordance with the Creative Commons Attribution-NonCommercial-NoDerivs 4.0 International License (CC BY-NC-ND 4.0), which permits the noncommercial replication and distribution of the article with the strict proviso that no changes or edits are made and the original work is properly cited (including links to both the formal publication through the relevant DOI and the license). See: https://creativecommons.org/licenses/by-nc-nd/4.0/.

\section{References}

1. Mayberry JF. Epidemiology and demographics of achalasia. Gastrointest Endosc Clin N Am 2001;11:235-48.

2. Podas T, Eaden J, Mayberry M, et al. Achalasia: a critical review of epidemiological studies. Am J Gastroenterol 1998;93:2345-7.

3. Goldblum JR, Whyte RI, Orringer MB, et al. Achalasia. A morphologic study of 42 resected specimens. Am J Surg Pathol 1994;18:327-37.

4. Williams VA, Peters JH. Achalasia of the esophagus: a surgical disease. J Am Coll Surg 2009;208:151-62.

5. Francis DL, Katzka DA. Achalasia: update on the disease and its treatment. Gastroenterology 2010;139:369-74.

6. Finley RJ, Rattenberry J, Clifton JC, et al. Practical approaches to the surgical management of achalasia. Am Surg 2008;74:97-102.

7. Neubrand M, Scheurlen C, Schepke M, et al. Long-term results and prognostic factors in the treatment of achalasia with botulinum toxin. Endoscopy 2002;34:519-23.

8. Storr M, Born P, Frimberger E, et al. Treatment of achalasia: the short-term response to botulinum toxin injection seems to be independent of any kind of pretreatment. BMC Gastroenterol 2002;2:19.

9. Heller E. Extramuköse cardiaplastik bein chronischen Cardiospasmus mit dilatation des Oesophagus. Mitt Grenzgeb Med Chir 1913;27:141-9.

10. Pellegrini C, Wetter LA, Patti M, et al. Thoracoscopic esophagomyotomy. Initial experience with a new approach for the treatment of achalasia. Ann Surg 1992;216:291-6; discussion 296-9.

11. Rosati R, Fumagalli U, Bonavina L, et al. Laparoscopic approach to esophageal achalasia. The American journal of surgery 1995;169:424-7.

12. Csendes A, Braghetto I, Henriquez A, et al. Late results of a prospective randomised study comparing forceful dilatation and oesophagomyotomy in patients with achalasia. Gut 1989;30:299-304.

13. Zaninotto G, Annese V, Costantini M, et al. Randomized controlled trial of botulinum toxin versus laparoscopic heller myotomy for esophageal achalasia. Ann Surg 2004;239:364-70.

14. Richards WO, Torquati A, Holzman MD, et al. Heller myotomy versus Heller myotomy with Dor fundoplication for achalasia: a prospective randomized double-blind clinical trial. Ann Surg 2004;240:405-12; discussion 412-5.

15. Patel DA, Lappas BM, Vaezi MF. An Overview of Achalasia and Its Subtypes. Gastroenterol Hepatol (N Y) 2017;13:411-21.

16. Kahrilas PJ, Kishk SM, Helm JF, et al. Comparison of pseudoachalasia and achalasia. Am J Med 1987;82:439-46.

17. Patel DA, Kim HP, Zifodya JS, et al. Idiopathic (primary) achalasia: a review. Orphanet J Rare Dis 2015;10:89.

18. Annese V, D'Onofrio V, Andriulli A. Botulinum toxin in long-term therapy for achalasia. Ann Intern Med 1998;128:696.

19. Mikaeli J, Islami F, Malekzadeh R. Achalasia: a review of Western and Iranian experiences. World J Gastroenterol 2009;15:5000-9.

20. Reynolds JC, Parkman HP. Achalasia. Gastroenterol Clin North Am 1989;18:223-55.

21. Shaligram A, Unnirevi J, Simorov A, et al. How does the robot affect outcomes? A retrospective review of open, laparoscopic, and robotic Heller myotomy for achalasia. Surg Endosc 2012;26:1047-50.

22. Ali AB, Khan NA, Nguyen DT, et al. Robotic and per-oral endoscopic myotomy have fewer technical complications compared to laparoscopic Heller myotomy. Surg Endosc 2020;34:3191-6.

23. Khashab MA, Kumbhari V, Tieu AH, et al. Peroral endoscopic myotomy achieves similar clinical response but incurs lesser charges compared to robotic heller myotomy. Saudi J Gastroenterol 2017;23:91-6.

24. Horgan S, Galvani C, Gorodner MV, et al. Roboticassisted Heller myotomy versus laparoscopic Heller myotomy for the treatment of esophageal achalasia: multicenter study. J Gastrointest Surg 2005;9:1020-9; 
discussion 1029-30.

25. Huffmanm LC, Pandalai PK, Boulton BJ, et al. Robotic Heller myotomy: a safe operation with higher postoperative quality-of-life indices. Surgery 2007;142:613-8; discussion 618-20.

26. Perry KA, Kanji A, Drosdeck JM, et al. Efficacy and durability of robotic Heller myotomy for achalasia: patient

doi: 10.21037/shc-2019-mies-09

Cite this article as: Chan EG, Sarkaria IS. Robotic assisted Heller myotomy: indications, techniques and outcomes. Shanghai Chest 2021;5:11. symptoms and satisfaction at long-term follow-up. Surg Endosc 2014;28:3162-7.

27. Sánchez A, Rodriguez O, Nakhal E, et al. Robotic-assisted Heller myotomy versus laparoscopic Heller myotomy for the treatment of esophageal achalasia: a case-control study. J Robot Surg 2012;6:213-6. 